\title{
Study on Hot Pressing Technology of Al-Fe-V-Si Quick Setting Sheet
}

\section{Powder}

\author{
Sumei Li ${ }^{\mathrm{a}}$, Jinjun Tang ${ }^{\mathrm{b}}$,Liqun $\mathrm{Hou}^{\mathrm{c}}$, Yulei Li ${ }^{\mathrm{d}}$, Zhaohui Gong ${ }^{\mathrm{e}}$
}

Ningbo Sub-academy of the National Weapons Science Research Academy, Ningbo 315103, China

alisumei52@163.com, bjinjun.tang@163.com, 'Liqunhou_nb@126.com, diyulei7395@163.com,

ezhaohuigong_nb@163.com

Key words: Billet temperature, die temperature, extrusion ratio, extrusion speed

Abstract: Hot pressing method although can effectively improve the density of the rapid hardening slice powder, but due to the rapid hardening slice heat ultrafine microstructure of aluminum alloy powder body approximately in to static pressure state, under the limited high loading stress condition, high temperature die impossible realization of powder fully densified. The density and properties of heat resistant aluminum alloy materials can be improved by the plastic deformation process such as extrusion and die forging. The project intends to by hot extrusion plastic deformation technology to improve the performance of the material by of different billet temperature, die temperature, extrusion ratio and extrusion speed and the influence of parameters on the material properties of plastic deformation, and ultimately determine the best extrusion technology.

\section{Introduction}

Because Al-Fe-V-Si alloy in the main strengthening phase al12 (Fe, V) 3Si dispersion particles as temperature sensitive particles[1,2], especially when the temperature of $480 \mathrm{DEG} \mathrm{C}$, and the insulation 100h, al12 (Fe, V) 3Si after melting to form stable acicular phase theta -Al13Fe4, and alloy yield strength, elongation and fracture toughness were significantly decreased; and when the heating temperature is lower than $425[3,4]$, even the holding $1000 \mathrm{~h}$, al12 (Fe, V) 3Si precipitated phase does not occur obviously armoring. Although reduce hot extrusion temperature can improve hot extrusion on the mechanical properties of the material[5], however, reduce the temperature will increase the material deformation resistance, hot extrusion temperature is too low will appear hot extrusion of various defects, such as: abutment and spallation.

\section{Materials and Methods}

The project team will be hot extrusion temperature (including mold temperature and billet temperature) is set to 390 degrees, 420 degrees, 450 degrees $\mathrm{C}$ and $480 \mathrm{C}$ value of the process test. Figure 1 for the hot extrusion temperature of $390 \mathrm{C}, 420 \mathrm{C}, 450 \mathrm{C}$ and $480 \mathrm{C}$, the heat preservation time of $1 \mathrm{H}$ extrusion bar material appearance quality photos. It can be seen that the hot extrusion temperature is 390 degrees Celsius, the temperature is too low, the deformation resistance is too large, and the cracking phenomenon is obvious. In the hot extrusion temperature is 420 degrees centigrade, the cracking phenomenon was not obvious, buckling phenomenon also exists in the local surface. With the hot extrusion temperature increased to more than 420 , the deformation capacity of the material was obviously enhanced, and the appearance quality of the extruded bar 
was relatively smooth.

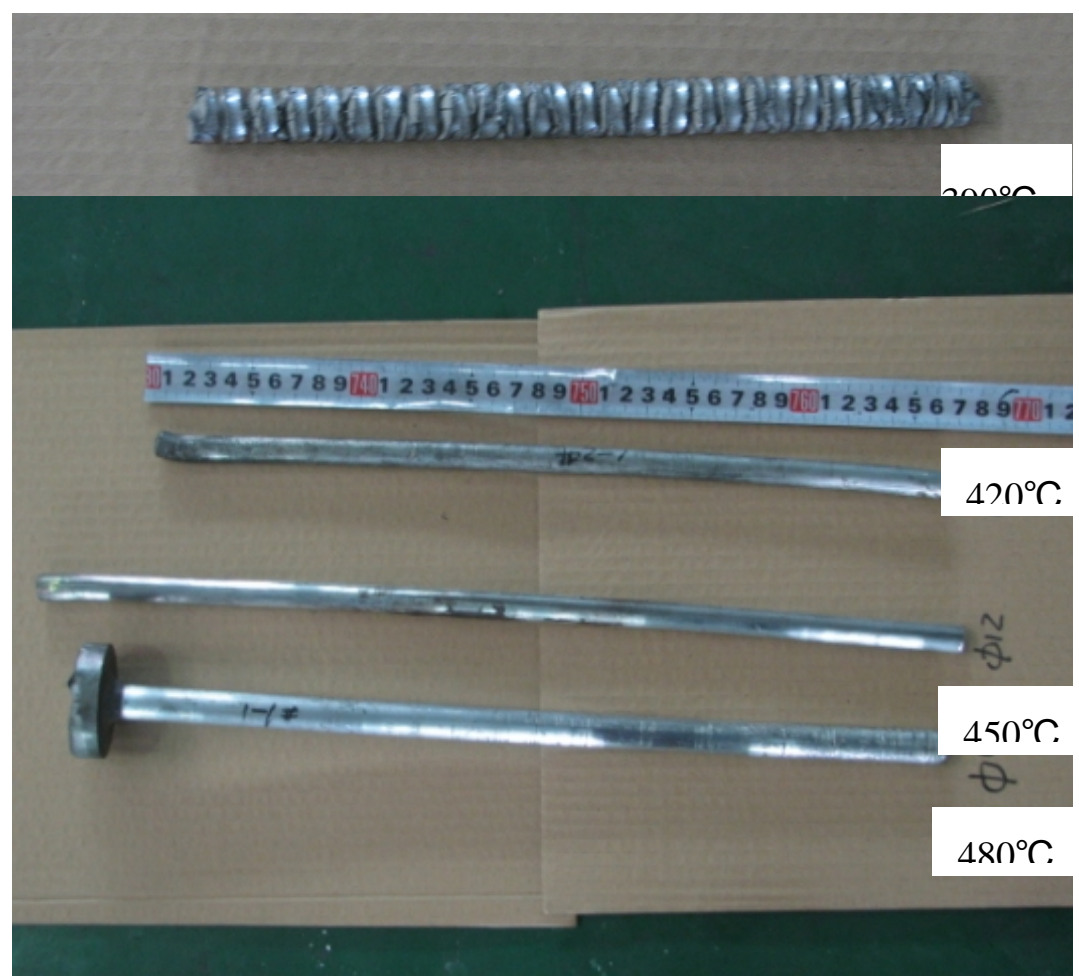

Fig.1 The appearance quality of extruded bar at different hot extrusion temperature

The extrusion speed is another key process parameter, the extrusion speed is too low, and the productivity is low. While the extrusion rate is too high and are easy to cause in the cracks on the surface of the bar. In addition, with the increase of the extrusion rate, more than $80 \%$ of the deformation energy is released in the form of heat energy, which can lead to the increase of the temperature of heat resistant aluminum alloy material. Deformation faster, time unit within the larger deformation, heat more, emit heat time is not enough, so temperature rise significantly. If the temperature exceeds a certain value $(>500 \mathrm{C})$, the main strengthening Al12 $(\mathrm{Fe}, \mathrm{V})$ 3Si phase in the $\mathrm{Al}-\mathrm{Fe}-\mathrm{V}-\mathrm{Si}$ alloy material will be severely rough, so that the mechanical properties of the final bar will have a serious impact. According to the actual situation of the press, the project team selected the press rate $10 \mathrm{~mm} / \mathrm{s}$ and a larger rate of $20 \mathrm{~mm} / \mathrm{s}$ to carry out the process test.

Fig. 2 the appearance quality of extruded bar for $10 \mathrm{~mm} / \mathrm{s}$ and $20 \mathrm{~mm} / \mathrm{s}$, respectively. As can be seen in the hot extrusion rate is $20 \mathrm{~mm}$, due to too fast, at the surface of the bar produced a large number of edge crack and surface crack; and when the extrusion rate adjustment is $10 \mathrm{~mm} / \mathrm{s}$, extrusion bar surface bright and clean and in good shape. According to the theory of extrusion and many experiments, the speed of extrusion bar is set to $10-15 \mathrm{~mm} / \mathrm{s}$.

As is shown in Fig 3, ultrafine microstructure heat-resistant aluminum alloy hot extrusion is finer, grain remain at about $2 \mathrm{~m}$, al12 (Fe, V) 3Si phase in the grain relatively homogeneous precipitation, also found that, by adding alloy precipitation

heat al12 (Fe, V) 3Si phase volume fraction of the highest volume fraction up to 33\%, FVS1012 precipitation heat al12 (Fe, V) 3Si phase of high volume fraction, volume fraction reached $11 \%$, FVS0612 ultrafine crystal precipitation heat al12 (Fe, V) 3Si phase volume fraction is small, the volume fraction of $3 \%$, alloy composition of heat-resistant phase volume fraction greater impact. 


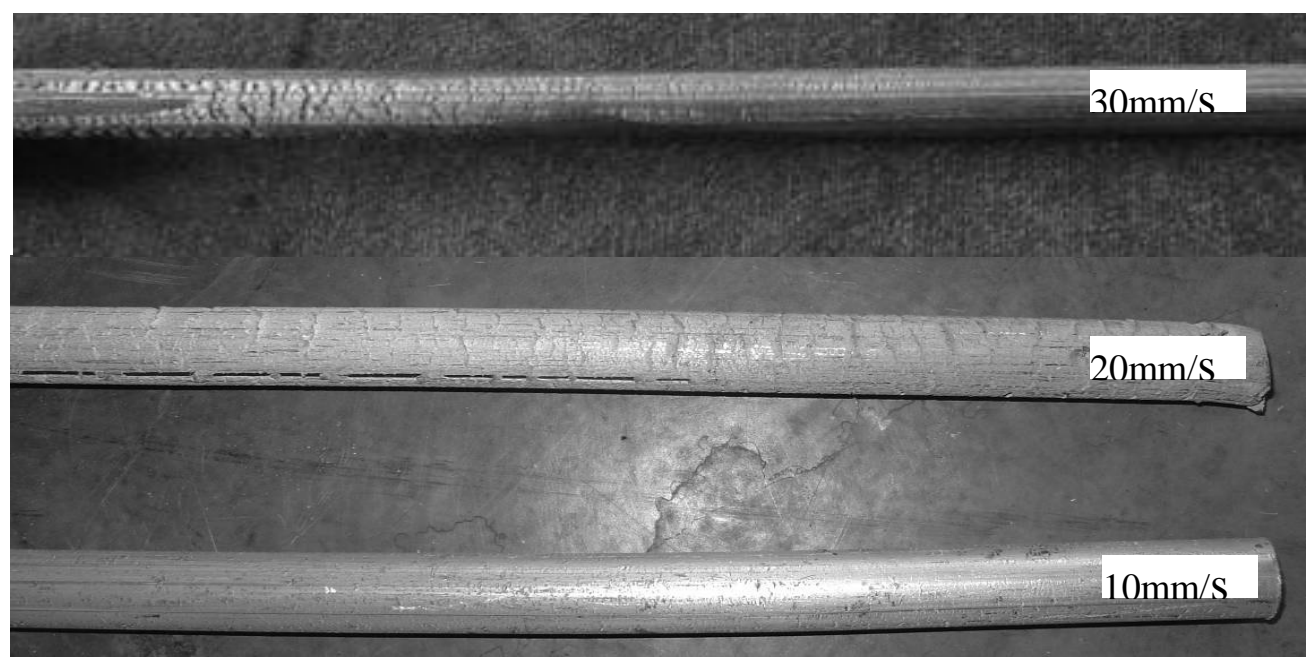

Fig. 2 The appearance quality of extruded bar under different extrusion speed (a) sintered state, (b) hot extruded state, (c) hot pressed state

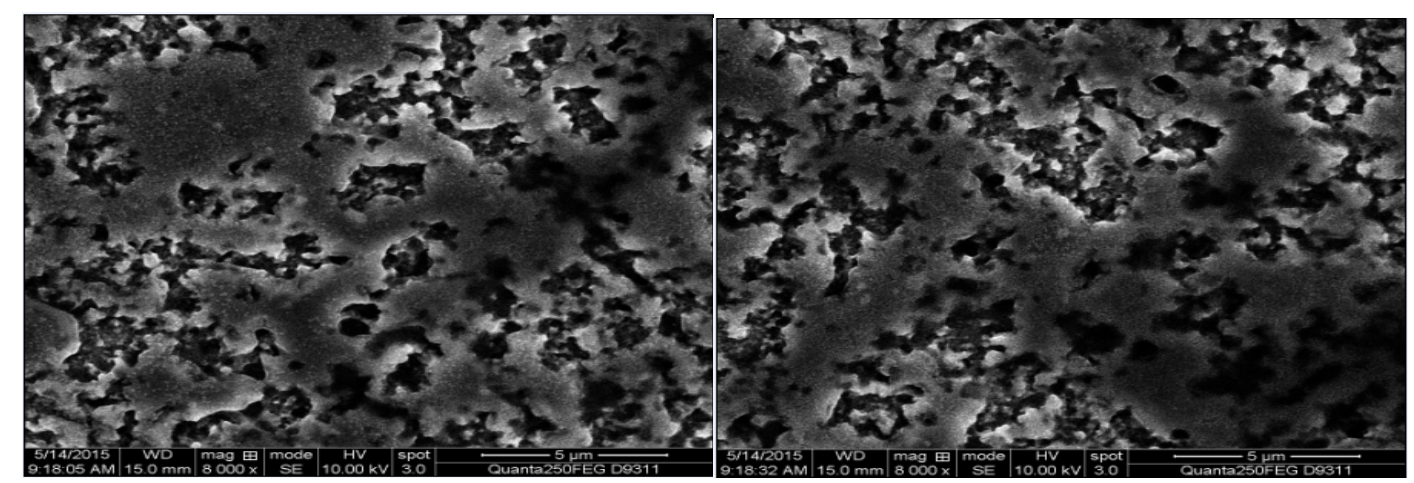

(a)FVS1212

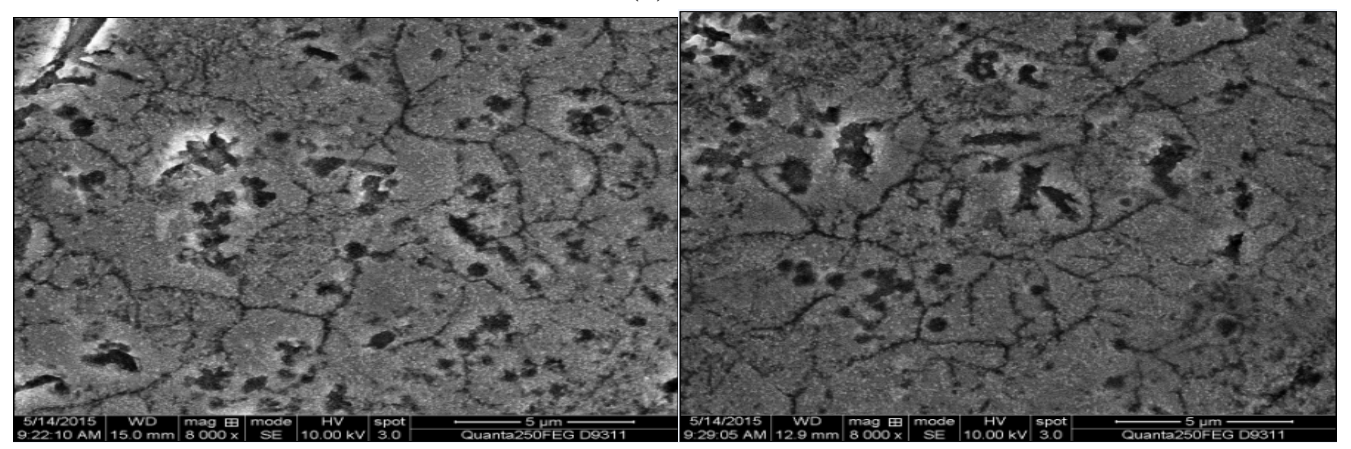

(b) FVS1012
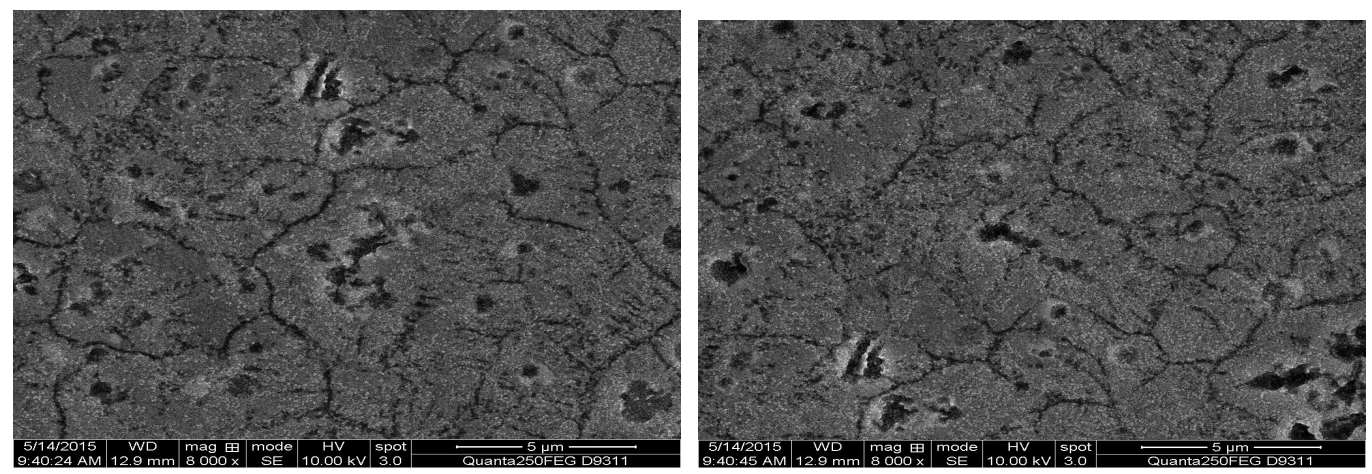

(c) FVS0612

Fig.3 Al-Fe-V-Si ultrafine grain and Al12 (Fe, V) 3Si phase 


\section{Conclusion}

When the temperature is less than 480 and greater than 500, the deformation resistance of the material decreases rapidly with the increase of temperature, the temperature range of 480-500. Therefore, in order to reduce the deformation resistance and increase the temperature of the hot extrusion, the significance is not significant between 480-500. Under the existing equipment conditions, it is necessary to consider the problem of determining the temperature of hot extrusion. Taking the above factors into consideration and combining with the actual mechanical properties of the hot extruded billet, we set the temperature of the hot extrusion die to 430. And the heating temperature of billet is 480 .

\section{References}

[1] Ravichandran K S, Dwarakadasa E S. Advanced Aerospace Al alloy. Journal of Metals, 1987,39(5):28-32

[2] Kim I S, Kim N J, Nam S W. Temperature dependence of the optimum particle size of Al-Fe-V-Si/SiCP composite. Scripta Metallurgical et Materials, 1995,32(11): 813-814

[3] Čadek J, Kuchařorá K, Zhu S J. High temperature creep behaviour of an Al-8.5Fe-1.3V-1.7Si alloy reinforced with silicon carbide particulates.Materials Science and Engineering A,2000,283(1-2): 172-180

[4] Cadek J, Kucharova K, Zhu S J. Creep behaviour of an Al-8.5Fe-1.3V-1.7Si-15SiCp composite at temperatures ranging from 873 to 948 K. Materials Science \& Engineering A, 328( 1-2 ) :283-290 [5] Zhu S J, Peng L M, Ma Z Y, et al. High temperature creep behavior of SiC whisker-reinforced Al-Fe-V-Si composite. Materials Science \& Engineering A,1996, A215(1-2):120-124 